\title{
HUBUNGAN PENGETAHUAN IBU DENGAN CARA MENYUSUI YANG BENAR PADA BAYI USIA 0-6 BULAN DI WILAYAH KERJA PUSKESMAS MUARA BUNGO I KABUPATEN BUNGO TAHUN 2017
}

\author{
Hardiana $^{1}$
}

\begin{abstract}
Abstrack
Following the World Health Organization (WHO) report in 2015, the Infant Mortality Rate (IMR) in the world was 33.6 per 1000 live births (WHO, 2016). Exclusive breastfeeding in the working area of Muara Bungo I Health Center is still low. Number of 0-6 months infants in the data were 46 babies, with they're who given exclusive breastfeeding as many as 25 (50.7\%). This research is analytical survey with cross sectional approach using total sampling method with 46 respondents using primary data in the working area of Muara Bungo I Health Center in 2017. Majority of respondents who had knowledge were 28 respondents (60.9\%) and who had wrong feeding method as many as 27 respondents (58.7\%). And $P$ value $=0.000$ ( $P$ value $<0.05)$ means there is a relationship between knowledge by the right way of breastfeeding in the working area of Muara Bungo I Health Center in 2017.
\end{abstract}

\section{Keywords : Knowledge, Right Way of Breast Feeding}

\section{PENDAHULUAN}

Angka kematian bayi merupakan indikator yang biasa digunakan untuk menentukan derajat kesehatan masyarakat, baik pada tingkat provinsi maupun nasional. Menurut laporan World Health Organization (WHO) tahun 2013, Angka Kematian Bayi (AKB) di dunia yaitu 33,6 per 1000 kelahiran hidup (WHO, 2015).

Berdasarkan hasil Survei Penduduk Antar Sensus (SUPAS) 2015 menunjukkan AKB di Indonesia sebesar 22,23 per 1.000 kelahiran hidup (Kemenkes RI, 2016).

Di Provinsi Jambi, angka kematian bayi berada diangka 34 per 1.000 kelahiran hidup. Dengan jumlah bayi yang meninggal paling banyak dilaporkan terdapat di Kabupaten Merangin (10 orang), sedangkan yang paling sedikit terdapat di Kabupaten Muaro Jambi dan Kabupaten Tanjab Barat (1 orang). Sedangkan di Kabupaten Bungo jumlah kematian

\footnotetext{
${ }^{1}$ Universitas Adiwangsa Jambi
}

bayi pada tahun 2014 yang dilaporkan adalah 4 orang (Dinkes Jambi, 2015).

Mengacu pada target renstra pada tahun 2015 yang sebesar 39\%, maka secara nasional cakupan pemberian ASI eksklusif pada bayi usia kurang dari enam bulan sebesar $55,7 \%$ telah mencapai target (Kemenkes, 2016).Cakupan pemberian ASI eksklusif di Provinsi Jambi tahun 2014 sebesar 73,62\%. Cakupan ini masih jauh di bawah target pencapaian pemberian ASI eksklusif nasional yaitu $80 \%$. Untuk pemberian ASI eksklusif tertinggi adalah Kabupaten Merangin sebesar $81,65 \%$ dan yang terendah adalah Kabupaten Bungo sebesar 55,77\% (Dinkes Provinsi Jambi, 2015).

Air Susu Ibu (ASI) adalah cairan kehidupan terbaik yang sangat dibutuhkan oleh bayi. ASI mengandung berbagai zat penting untuk tumbuh kembang bayi dan sesuai dengan kebutuhannya (Rukiyah dkk, 2011, 22). 
Menyusui merupakan cara pemberian makan yang diberikan secara langsung oleh ibu kepada anaknya, namun seringkali ibu menyusui kurang memahami dan kurang mendapatkan informasi, bahkan seringkali ibu-ibu mendapatkan suatu informasi yang salah tentang manfaat ASI eksklusif itu sendiri, tentang bagaimana cara menyusui atau langkah-langkah menyusui yang benar kepada bayinya, dan kurang informasi yang diberikan tentang dampak apabila ASI eksklusif itu tidak diberikan dan apa yang harus dilakukan bila timbul kesukaran dalam menyusui secara eksklusif kepada bayinya (Nugroho, dkk, 2014, 47).

Pemberiaan ASI yang benar dimulai dari waktu dan teknik menyusui yang benar. Banyak sedikitnya ASI berhubungan langsung dengan posisi ibu saat menyusui. Posisi yang tepat akan mendorong keluarnya ASI secara maksimal (Maryunani, 2009,79).

Keberhasilan menyusui bukan sesuatu yang datang dengan sendirinya, tetapi merupakan keterampilan yang perlu diajarkan. Agar ibu berhasil menyusui, perlu dilakukan berbagai kegiatan saat antenatal, intranatal dan postnatal. Seringkali kegagalan menyusui disebabkan oleh kesalahan memposisikan dan melekatkan bayi. Puting ibu jadi lecet, ibu jadi segan menyusui, produksi ASI berkurang dan bayi jadi malas menyusu (Prawirohardjo, 2009, 376).

Berdasarkan data register di Puskesmas Muara Bungo I, bayi yang mendapatkan ASI eksklusif diwilayah kerja Puskesmas Muara Bungo I yaitu:
Tabel 1

Cakupan Pemberian Asi Eksklusif

Pada Bayi 0-6 bulan Wilayah Kerja Puskesmas Muara Bungo I

Tahun 2017

\begin{tabular}{|c|l|c|c|c|}
\hline \multirow{2}{*}{ No } & Kelurahan & $\begin{array}{c}\text { Jumlah } \\
\text { Bayi 0- } \\
\text { 6 } \\
\text { Bulan }\end{array}$ & \multicolumn{2}{|c|}{$\begin{array}{c}\text { Pemberian } \\
\text { ASI Pada } \\
\text { Bayi 0-6 } \\
\text { Bulan }\end{array}$} \\
\cline { 4 - 6 } A & $\begin{array}{l}\text { Pasar } \\
\text { Bungo }\end{array}$ & & & X \\
\hline 1 & $\begin{array}{l}\text { Bungo } \\
\text { Barat }\end{array}$ & 7 & 4 & 3 \\
\hline 2 & $\begin{array}{l}\text { Bungo } \\
\text { Timur }\end{array}$ & 5 & 3 & 2 \\
\hline 3 & Jaya Setia & 10 & 6 & 4 \\
\hline 4 & Tj. Gedang & 17 & 9 & 8 \\
\hline 5 & Bt. Bungo & 7 & 4 & 3 \\
\hline & Jumlah & 46 & 26 & 20 \\
\hline
\end{tabular}

Sumber : Data Register Puskesmas Muara Bungo I

Dari data diatas dapat disimpulkan bahwa pemberian ASI eksklusif di wilayah kerja Puskesmas Muara Bungo I masih rendah. Jumlah bayi 0-6 bulan 46 bayi, dengan jumlah pemberian ASI eksklusif sebanyak 26 (56.5\%), untuk itu penulis ingin mengetahui pengetahuan ibu yang memiliki bayi usia 0-6 bulan tentang ASI eksklusif dengan cara menyusui yang benar diwilayah kerja Puskesmas Muara Bungo I.

Saya melakukan survey awal dengan mewawancara 10 ibu menyusui di wilayah kerja Puskesmas Muara Bungo I, diperoleh hasil bahwa 7 orang mempunyai pengetahuan yang kurang dengan cara menyusui yang benar, dan 3 orang mempunyai pengetahuan yang baik dengan cara menyusui yang benar. Hal ini dikarenakan kurangnya pengetahuan 
dan informasi dari tenaga kesehatan tentang cara menyusui yang benar.

Berdasarkan uraian diatas, maka peneliti tertarik untuk mengetahui hubungan pengetahuan ibu dengan cara menyusui yang benar pada bayi usia 0-6 bulan diwilayah kerja Puskesmas Muara Bungo I tahun 2017.

\section{METODE PENELITIAN}

Desain pada penelitian ini adalah metode survey analitik yaitu survey atau penelitian yang mencoba menggali bagaimana dan mengapa fenomena kesehatan itu terjadi. Penelitian ini menggunakan pendekatan Cross Sectional, yaitu suatu penelitian untuk mempelajari dinamika korelasi antara faktor-faktor resiko dengan efek, dengan cara pendekatan, observasi atau pengumpulan data (Notoatmodjo, 2012, 37).

\section{HASIL DAN PEMBAHASAN}

Analisis Univariat

Distribusi Frekuensi Pengetahuan Ibu pada Bayi Usia 0-6 Bulan di Wilayah Kerja Puskesmas Muara Bungo I

Tabel 2

Distribusi Frekuensi Pengetahuan Ibu pada Bayi Usia 0-6 Bulan di Wilayah

Kerja Puskesmas Muara Bungo I

\begin{tabular}{crc}
\hline $\begin{array}{c}\text { Pengetahua } \\
\text { n }\end{array}$ & $\begin{array}{c}\text { Frekuens } \\
\text { i }\end{array}$ & $\begin{array}{c}\text { Persentas } \\
\mathbf{e}(\boldsymbol{\%})\end{array}$ \\
\hline Baik & 18 & 39,1 \\
Kurang & 28 & 60,9 \\
\hline Total & 46 & 100 \\
\hline
\end{tabular}

Berdasarkan tabel di atas menunjukkan bahwa mayoritas responden memiliki pengetahuan kurang sebanyak 28 responden $(60,9 \%)$.
Distribusi Frekuensi Cara Menyusui yang Benar pada Bayi Usia 0-6 Bulan di Wilayah Kerja Puskesmas Muara Bungo I

Tabel 3

Distribusi Frekuensi Cara Menyusui

yang Benar pada Bayi Usia 0-6 Bulan

di Wilayah Kerja Puskesmas Muara Bungo I

\begin{tabular}{ccc}
\hline $\begin{array}{l}\text { Cara } \\
\text { Menyusui }\end{array}$ & Frekuensi & $\begin{array}{c}\text { Persentase } \\
(\boldsymbol{\%})\end{array}$ \\
\hline Benar & 19 & 41,3 \\
Salah & 27 & 58,7 \\
\hline Total & 46 & 100 \\
\hline
\end{tabular}

Berdasarkan tabel di atas menunjukkan bahwa mayoritas responden memiliki cara menyusui yang salah sebanyak 27 responden $(58,7 \%)$.

\section{Analisis Bivariat}

Distribusi Frekuensi Hubungan Pengetahuan Ibu dengan Cara Menyusui yang Benar pada Bayi Usia 0-6 Bulan di Wilayah Kerja Puskesmas Muara Bungo I

Tabel 4

Distribusi Frekuensi Hubungan Pengetahuan Ibu dengan Cara Menyusui yang Benar pada Bayi Usia 0-6 Bulan di Wilayah Kerja Puskesmas Muara Bungo I

\begin{tabular}{|c|c|c|c|c|c|c|c|}
\hline \multirow{3}{*}{ Pengetahuan } & \multicolumn{4}{|c|}{$\begin{array}{c}\text { Cara Menyusui yang } \\
\text { Benar }\end{array}$} & \multirow{2}{*}{\multicolumn{2}{|c|}{ Total }} & \multirow{2}{*}{$\begin{array}{r}P \\
\text { value }\end{array}$} \\
\hline & \multicolumn{2}{|c|}{ Benar } & \multicolumn{2}{|c|}{ Salah } & & & \\
\hline & $\mathbf{N}$ & $\%$ & n & $\%$ & n & $\%$ & \\
\hline Baik & 15 & 32,6 & 3 & 6,5 & 18 & 39,1 & 0,000 \\
\hline Kurang & 4 & 8,7 & 24 & 52,2 & 28 & 60,9 & \\
\hline Total & 19 & 41,3 & 27 & 58,7 & 46 & 100 & \\
\hline
\end{tabular}

Berdasarkan tabel diatas dari hasil uji fisher exact test diperoleh hasil bahwa $P$ value $=0,000(P$ value $<0,05)$ artinya ada hubungan antara pengetahuan ibu menyusui dengan 
cara menyusui yang benar di Wilayah Kerja Puskesmas Muara Bungo I Tahun 2017.

\section{PEMBAHASAN}

Analisis Univariat

Pengetahuan Ibu Menyusui pada Bayi Usia 0-6 Bulan di Wilayah Kerja Puskesmas Muara Bungo I.

Berdasarkan hasil penelitian yang didapat menunjukkan bahwa mayoritas responden memiliki pengetahuan kurang sebanyak 28 responden ( 60,9\%).

Menurut asumsi peneliti, mayoritas responden berpengetahuan kurang dalam penelitian ini disebabkan beberapa faktor, antara lain rendahnya tingkat pendidikan, faktor lingkungan serta kurangnya mendapatkan informasi atau pengetahuan mengenai cara menyusui yang benar. Peran tenaga kesehatan sangat diperlukan dalam meningkatkan pengetahuan ibu menyusui mengenai cara menyusui yang benar, hal ini dapat dilakukan melalui penyuluhan.

Menurut penelitian yang dilakukan oleh Fatimah \& Fauziah di Klinik PKU Muhammadiyah Sampangan Surakarta (2014). Hubungan Pengetahuan dengan Sikap Ibu Menyusui Tentang Cara Menyusui Yang Benar di Klinik Utama PKU Muhammadiyah Sampangan Surakarta Tahun 2014 yang mengatakan bahwa tingkat pengetahuan ibu menyusui tentang cara menyusui yang benar yaitu dari 32 Responden yang memiliki pengetahuan Cukup 25 responden $(78,1 \%)$, berpengeahuan Baik 4 responden $(12,5 \%)$ dan berpengetahuan Kurang 3 Responden $(9,4 \%)$.

Pengetahuan adalah sesuatu yang diketahui berkaitan dengan proses pembelajaran. Proses belajar ini sesuatu dipengaruhi berbagai faktor dari dalam, seperti motivasi dan faktor luar berupa sarana informasi yang tersedia, serta keadaan sosial budaya (Budiman \& Riyanto, 2014, 3).

\section{Cara Menyusui Yang Benar pada Bayi Usia 0-6 Bulan di Wilayah Kerja Puskesmas Muara Bungo.}

Berdasarkan hasil penelitian menunjukkan bahwa dari 46 responden diketahui mayoritas responden memiliki cara menyusui yang salah sebanyak 27 responden $(58,7 \%)$.

Menurut asumsi peneliti, hasil penelitian tentang cara menyusui yang benar mayoritas baik karena perilaku ini dituntut dorongan dari dalam sedangkan dorongan merupakan usaha untuk memenuhi kebutuhan. Ibu menyusui memiliki kebutuhan untuk menjaga kesehatan dirinya dan bayinya, yang dipersiapkan agar dapat memberikan ASI dengan sempurna kepada bayinya.

Menurut penelitian yang dilakukan oleh Sri Iyani, Arifal Aris STIKES Muhammadiyah Lamongan (2009) mengenai Hubungan Pengetahuan Ibu dengan Cara Menyusui yang Benar di BPS Yuliana Lamongan Tahun 2009 yang mengatakan bahwa dari 40 responden sebagian besar ibu yang cara menyusui yang benar $19(47,5 \%)$ responden, sebagian ibu yang cara menyusui yang kurang benar $13(32,5 \%)$ responden dan sebagian kecil ibu yang cara menyusui yang salah $8 \quad(20 \%)$ responden.

Cara menyusui yang benar adalah cara memberikan ASI kepada bayi dengan perlekatan dan posisi ibu dan bayi dengan benar. Menyusui dengan cara yang tidak benar dapat mengakibatkan puting susu lecet, ASI

Hubungan Pengetahuan Ibu Dengan Cara Menyusui Yang Benar Pada Bayi Usia 0-6 Bulan Di Wilayah Kerja Puskesmas Muara Bungo I Kabupaten Bungo Tahun 2017 
tidak keluar optimal sehingga mempengaruhi produksi ASI selanjutnya atau bayi enggan menyusu. Salah satu penyebab kegagalan menyusui adalah disebabkan karena kesalahan ibu dalam memposisikan dan meletakkan bayi saat menyusu (Fatimah \& Fauziah, 2014).

\section{Analisis Bivariat}

Hubungan Pengetahuan Ibu dengan Cara Menyusui yang Benar pada Bayi usia 0-6 Bulan di Wilayah Kerja Puskesmas Muara Bungo I Kabupaten Bungo Tahun 2017.

Dari hasil uji fisher exact test diperoleh hasil bahwa $P$ value $=0,000$ $(P$ value $<0,05)$ artinya ada hubungan antara pengetahuan ibu menyusui dengan cara menyusui yang benar di Wilayah Kerja Puskesmas Muara Bungo I Tahun 2017.

Menurut asumsi peneliti, ada hubungan antara pengetahuan dengan cara menyusui yang benar dalam penelitian ini disebabkan karena mayoritas ibu menyusui dengan pengetahuan baik menyusui dengan sangat baik. Sedangkan ibu menyusui dengan pengetahuan kurang menyusui dengan cukup. Hal ini berarti ada kesesuaian antara teori dengan fakta yang ada.

Berdasarkan fakta diatas diharapkan tenaga kesehatan khususnya bidan untuk terus meningkatkan kesadaran ibu menyusui dalam memberikan ASI serta lebih giat dalam memberikan pengetahuan dan informasi kepada ibu menyusui mengenai cara menyusui yang benar.

\section{SIMPULAN}

Berdasarkan hasil penelitian tentang Hubungan Pengetahuan Ibu dengan Cara Menyusui yang Benar di Wilayah Kerja Puskesmas Muara
Bungo I tahun 2017, dapat diambil Kesimpulan sebagai berikut:

1. Mayoritas responden memiliki pengetahuan kurang.

2. Mayoritas responden memiliki cara menyusui yang salah.

3. Ada hubungan antara pengetahuan ibu dengan cara menyusui yang benar pada bayi usia 0-6 bulan di Wilayah Kerja Puskesmas Muara Bungo I Kabupaten Bungo Tahun 2017.

\section{Saran}

1. Bagi Ibu Menyusui

Diharapkan ibu menyusui mencari dan mendapatkan informasi mengenai ASI serta cara menyusui yang benar, sehingga ibu dapat menyusui dengan optimal sedangkan bagi suami atau keluarga lebih mendukung ibu untuk menyusui bayinya dengan benar.

2. Bagi Puskesmas Muara Bungo I

Diharapkan tenaga kesehatan khususnya bidan meningkatkan kesadaran ibu menyusui untuk memberikan ASI eksklusif kepada bayinya, serta lebih giat dalam memberikan pengetahuan dan informasi tentang cara menyusui yang benar. Agar ibunya mau termotivasi setelah tenaga kesehatan memberikan penyuluhan tentang cara menyusui yang benar dan manfaat ASI.

\section{DAFTAR PUSTAKA}

Angsuko, Dhames. 2009. Hubungan Pengetahuan Ibu Tentang Cara Menyusui Dengan Perilaku Menyusui Bayi Usia 0-6 Bulan Di Bidan Yuda, Klaten.

Ariani, Ayu Putri. 2014. Aplikasi Metodologi Penelitian Kebidanan dan Kesehatan Reproduksi. Yogyakarta: Nuha Medika. 
Aris Arifal. 2009. Hubungan Pengetahuan Ibu dengan Cara Menyusui Yang Benar. http://eprints.umpo.ac.id/2060/, diakses oleh Anita Helfiana, 16 Juni 2017, 09.20 WIB)

Astutik, Reni Yuli. 2015. Buku Ajar Asuhan Kebidanan Masa Nifas dan Menyusui. Jakarta : Trans Info Media.

Asih, Yusari \& Risneni. 2016. Buku Ajar Asuhan Kebidanan Nifas dan Menyusui. Dilengkapi dengan evidence based practice dan Daftar Tilik Asuhan Nifas. Jakarta : TIM

Budiman \& Riyanto, Agus. 2014. Kapita Selekta Kuesioner. Pengetahuan dan Sikap dalam Penelitian Kesehatan. Jakarta. Salemba Medika.

Dinkes Provinsi Jambi. 2015. Profil Kesehatan Provinsi Jambi 2014. http://www.jambiprov.go.id.

Fatimah, Siti dan Fauziah. 2014. Hubungan Pengetahuan Dengan Sikap Ibu Menyusui Tentang Cara Menyusui Yang Benar.

Kementerian Kesehatan RI. 2016. Profil Kesehatan Indonesia 2015. http://www.kemkes.go.id.

Maryunani, Anik. 2009. Asuhan Pada Ibu Dalam Masa Nifas (Postpartum). Jakarta : Trans Info Media

Menyusui Dini, ASI Eksklusif dan MAnajemen Laktasi. Jakarta : Trans Info Media.

Roito H, Juraida. Dkk. 2013. Asuhan Kebidanan Ibu Nifas \& Deteksi Dini Komplikasi. Jakarta: EGC.

Notoatmodjo, S. 2010. Metodologi Penelitian Kesehatan. Jakarta: Rineka Cipta.
2012. Metodologi

Penelitian Kesehatan. Jakarta: Rineka Cipta. . 2012. Ilmu Perilaku

Kesehatan. Jakarta : Rineka Cipta.

Nugroho, Taufan, dkk. 2014. Buku Ajar Asuhan Kebidanan Nifas (Askeb III). Yogyakarta : Nuha Medika.

Prawirohardjo, Sarwono. 2009. Ilmu Kebidanan. Jakarta: YBPSP

Roito H, Juraida. Dkk. 2013. Asuhan Kebidanan Ibu Nifas \& Deteksi Dini Komplikasi. Jakarta: EGC.

Rukiyah, Ai yeyeh. Dkk. 2011. Asuhan Kebidanan III (Nifas). Jakarta: Trans Info Media.

WHO. 2015. World Health Statistic 2015. World Health Organization 2015. http://www.who.int 